\title{
Dissemination of Salmonella bacilli through Carriers and Domestic Water Sources in Enugu Urban/Peri-Urban of Nigeria
}

\author{
Clara I. Eleazar ${ }^{*}$, Iniekong P. Philip ${ }^{1}$, Bryan 0. Ogeneh ${ }^{2}$ \\ ${ }^{1}$ University of Nigeria, Enugu Campus, Nsukka, Nigeria \\ ${ }^{2}$ Federal University, Oye Ekiti, Nigeria \\ Email: "claraidara@yahoo.co.nz
}

Received 15 March 2015; accepted 21 April 2015; published 24 April 2015

Copyright (C) 2015 by authors and Scientific Research Publishing Inc.

This work is licensed under the Creative Commons Attribution International License (CC BY). http://creativecommons.org/licenses/by/4.0/

\section{(c) (i) Open Access}

\section{Abstract}

Salmonella bacilli infection has remained an important health problem in the developing world. The transmission of $S$. typhi most often occurs through food and water, which have been contaminated by faeces from carriers and infected humans. Prevalence of carriers is a factor in transmission. The population under study lacked access to clean and safe water. Patients practiced self medication with inadequate dosing leading to relapsing infections and chronic carrier state. With this, there is a need to determine the actual dissemination index of the salmonella organism in the locality. The isolation from stool, blood and water samples were made using enrichment broths and selective media. Identification of isolates was carried out using standard methods. Characterization was done using $O$ and $H$ polyvalent sera. The total number of infected subjects within the 15 household was $22(36.7 \%)$ among whom 10 (16.7\%) were confirmed carriers. The total number/percentage infected by carrier contact was 9 (39.1\%). Consumption of well water gave rise to the highest $(60.0 \%)$ attack rate of typhoid fever infection. The continuance exposure to contaminated water source could be consistent to incessant and relapsing typhoid fever attacks in exposed individuals. Chronic carriers pose great risk to other members of the household, therefore regular screening is required.

\section{Keywords}

Salmonella, Carriers, Water

\footnotetext{
${ }^{*}$ Corresponding author.
} 


\section{Introduction}

Salmonella bacilli infection has remained an important health problem in the developing world [1] [2]. Salmonella typhi/paratyphi is the main cause of typhoid/paratypoid fever. Typhoid fever is a disease of major public health importance in Nigeria and indeed the rest of Africa [3]-[5].

Most strains of salmonella are peritrichously flagellated and hence motile. Compared to other Gram negative rods, the salmonellae are relatively more resistant to various environmental conditions, including drying, salting, smoking and freezing, for varying lengths of time and, hence, survive in many foods as well as frozen water. The pathogen would survive for days in groundwater, pond water, or seawater, and for months in contaminated eggs and frozen oysters [6]; but would be killed when exposed to temperatures of $60^{\circ} \mathrm{C}-70^{\circ} \mathrm{C}$ for 15 minutes $[7]$.

The transmission of S. typhi most often occurs through food and water, which have been contaminated by faeces or urine from infected humans [8]. Individuals at their sub-clinical stage are more important source of contamination than clinical cases [9]. About 30\% of those infected may become transient carriers and 5\% become long-term carriers. Also about $10 \%$ of untreated typhoid fever patients excrete the bacteria for 3 months after onset of symptoms. However, some patients excreting $S$. typhi have no history of typhoid fever [10].

Epidemics originating from water contamination are particularly explosive being that infection ensues easily, since the gastric acid that would have inactivated the pathogen is diluted by water during drinking. Explosive epidemics are also made possible by large population using the same water source [11]. Poverty, uncontrolled urbanization and inadequate infrastructure do contribute to the contamination of water supplies [12]-[14].

In the many part of Nigeria safe drinking water and proper sanitation measures are still lacking giving rise to increase incidence cases of enteric fever. Recently, there has been a great surge and demand of commercially packaged sachet water to supplement the scarce water supply. This invariably results in high rate of consumption of such products. This too poses a threat and danger to health; as the hygienic condition and safety of such water cannot be attested for. The scarce supply of pipe-borne water which has remained the only source of drinking water is likely to be contaminated too through rusted and perforated pipes. As a matter of fact, the unreported cases of water-borne infections in Nigeria, particularly typhoid fever, have been more than those reported to hospitals [15]. The objective of this research is to evaluate the distribution rate of Salmonella bacilli in domestic water sources, carry out some case study on subjects exposed to the water sources and determine carrier rates among the exposed.

\section{Methods}

\subsection{Study Area}

The study took place in Enugu State, south east of Nigeria. Enugu State is made up of rural, urban and some periurban units. The urban units of the state capital are zoned into Enugu east, west, North and south. Majority of the urban and the peri-urban dwellers lack assess to portable and safe drinking water.

\subsection{Subjects and Sampling}

The representative population (population at risk) was defined in terms of risk of exposure. This included subjects who have been previously exposed and those that had manifested symptoms of the typhoid fever disease or exposed to the disease within the previous six months or more. A total of 60 subjects were randomly selected from 15 household living within the typhoid endemic zones; while seven subjects fed from same contaminated water source were used in surveillance study. Stool and blood samples were obtained from each of the subjects. Blood were drawn aseptically using $10 \mathrm{ml}$ syringe and needle (Weintein, 1996). About 5 - 8 ml of blood was obtained from adults and 1 - $3 \mathrm{ml}$ from each child. The blood samples were collected into vacutainner (plain sterile $15 \mathrm{ml}$ volume stoppered glass tubes). The blood was allowed to clot and after centrifugation the serum was separated from the clot. The serum was used for serological screening while the clot was poured into sterile universal containers and minced with scissors. About $2 \mathrm{ml}$ of bile salt broth was added to the clotted blood and incubated. Each tube was carefully labeled with the patients number already indicated in the laboratory request forms. For collection of stool samples the subjects were provided with clean wide-mouthed containers with screw covers or sterile containers with wooden spatular. Peanut-sized stool specimens were introduced into these and taken to the laboratory without delay. 
The total number of water samples collected and analysed was 1000, consisting of 200 each of 5 different water sources. The water types were as follows: bottled water, sachet water, pipe borne water, well water and surface tank water. Well water was collected from different wells. Pipe borne water was from different locations, bottle water and sachet water were from different batches Pipe borne water was collected as follows: by cleaning the outside nozzle of the tap $70 \%$ alcohol to remove any grease or dirt. The tap was turned on full and allowed to run to waste for about a minute. The tap nozzle was sterilized using the flame from spirit lamp and allowed to cool. The sample bottles were filled by a gentle flow of water and the cap replaced. For collection of Stream and Shallow Surface Well Water, the cap and cover of the sterile sample bottles were aseptically removed, and the mouths of the bottle faced towards the flow of water. The necks of the bottles were plunged downwards $30 \mathrm{~cm}$ below the water surface and then tilted slightly sidewards to let them fill completely before carefully replacing the caps. Where there was no current the bottles were pushed horizontally until they were filled.

\subsubsection{Blood Samples Analyses}

Widal tests were carried out on all the blood samples collected from the apparently ill subjects. Commercially prepared stocks of the Widal agglutination kits were stored at $2^{\circ} \mathrm{C}-8^{\circ} \mathrm{C}$ in the refrigerator. A drop of serum was placed into each row of circles on paper cards. One drop of each of the negative and positive control sera were dispensed unto two additional circles. One drop of the appropriate antigen suspension was added to each circle next to the sample to be tested. Next, the mixtures were rocked gently on the card for a period of two minutes. The reactions were observed immediately under a suitable light source for any degree of agglutination as positive reaction.

For the quantitative test six clean plain tubes were placed in racks in two rows and $0.9 \mathrm{ml}$ of normal saline ( $0.85 \%$ sodium chloride) was delivered into the first tube in each row and $0.5 \mathrm{ml}$ into others. Next, $0.1 \mathrm{ml}$ of the test sera were delivered into the first tubes and mixed. Quantities of $0.5 \mathrm{ml}$ volume of the diluted sera from the first tubes were delivered into the second tubes to obtain two-fold dilutions. This procedure was repeated up till the last tube (tube 6) and $0.5 \mathrm{ml}$ of the diluted sera was discarded from tube 6. (At this stage the serial doubling dilutions of 1 in 20 to 1 in 640 was obtained). Similar set-up was prepared for the positive and negative control sera. Then, 0.5 of appropriate antigen suspension was added to each (containing serum dilution). The two racks were shaken carefully to mix the antigens and the sera. Experiments with somatic $\mathrm{O}$ antigen were incubated at $50^{\circ} \mathrm{C}$ for 4 hours in water bath while those containing the flagella $\mathrm{H}$ antigen were incubated for 2 hours in the same temperature. After incubation the result of control tubes were read first by examining the pattern of the sediment and then shaking the tubes gently.

The patients' blood samples were also cultured. Clot culture technique was used as against standard cultural techniques. The clotted blood samples were transferred into labeled sterile universal containers. The clots were lysed by mincing with sterile scissors to free any salmonella organisms trapped in the clot. About $5 \mathrm{ml}$ of the prepared bile salt broth were pipetted into each of the containers. These were incubated overnight at $37^{\circ} \mathrm{C}$ for 18 to 24 hours. After this subcultures were made from each of the containers unto freshly prepared and dried SSA (Biotec) and incubated at $37^{\circ} \mathrm{C}$.

\subsubsection{Stool Samples Analyses}

The stool samples of all suspected carriers were cultured. These were first inoculated into the enrichment medium (Selenite-F broth) and after incubation for 24 hours at $37^{\circ} \mathrm{C}$ each was sub-cultured into Salmonella-Shigella agar (SSA). The SSA plates were incubated overnight at $37^{\circ} \mathrm{C}$ and examined for growth.

\subsubsection{Water Samples Analysis (Membrane Filtration Method)}

About $100 \mathrm{ml}$ of each water sample were filtered through a membrane which retained the bacteria on its surface. The membrane was removed aseptically and placed on the Salmonella-Shigella agar media. This was incubated at $37^{\circ} \mathrm{C}$ for 24 hours. After incubation the colony growth of each water sample were identified and confirmed.

\subsection{Characterization and Identification of Isolates}

\subsubsection{Sugar Fermentation Tests}

Nutrient broth (Lab. M) was prepared. Bijou bottles containing the basal medium and appropriate prepared carbohydrate (mannitol, maltose, dulcitol, sucrose and glucose) were inoculated with drop of the nutrient broth 
suspension of the test isolate and were loosely capped and incubated at $35^{\circ} \mathrm{C}$ overnight. Each was observed for change in colour from amber to red and for gas production (in the medium filled inverted Durham tube).

\subsubsection{Urease Test}

The test organisms were inoculated heavily on the entire slope surface of the urea agar slants prepared in caped tubes. The tubes were placed in racks and incubated at $37^{\circ} \mathrm{C}$ up to 48 hours. Tubes were thereafter examined for change of colour from plain to pink.

\subsubsection{Hydrogen Sulphide Production}

Test organisms were inoculated into the triple sugar iron agar (Lab. M) slants contained in test tubes. These were incubated at $35^{\circ} \mathrm{C}-37^{\circ} \mathrm{C}$ for up to 48 hours.

After incubation the TSI agar media were checked for blackening and change in colour from amber to red at the bottom (butt) of the tube.

\subsection{Serological Identification (Serotyping)}

Suspected colonies were picked and sub-cultured unto moist nutrient agar slopes in MacCartney bottles. These were incubated for minimum of 4 hours.

One to two loopfulls of the agar cultures were mixed with normal saline on clean microscope slides to form a paste. A drop each of the $\mathrm{O}$ and $\mathrm{H}$ polyvalent sera were added and further mixed with the organisms on the slide. Positive results were indicated by visible agglutination within 30 seconds. Slide tests were repeated for the positive cultures using single factor sera. Stock of the bacteriologically confirmed isolates were made on nutrient agar (NA) slants and stored at $4^{\circ} \mathrm{C}$ with intermittent fortnightly subcultures to keep the isolate viable.

\section{Results}

The number and rate of subjects infected by carrier contact within household is shown in Table 1 . Amongst The 60 subjects living within the 15 household, 23 (38.3\%) were exposed. The total number of infected subjects within the 15 household was 22 (36.7\%) among whom 10 (16.7\%) were confirmed carriers by stool isolates of Salmonella enterica enterica typhi. The total number/percentage infected by carrier contact was $9(39.1 \%)$. The rates of infection ranged from $20 \%$ to $100 \%$, only one household had $0.0 \%$ infection rates of carriers ranged between $20.0 \%$ and 50\%. Eight households had no carriers living among them. While all the households that had no carriers recorded no incidence of carrier contact cases, only 2 households with carriers had no carrier contact case. The result of case study of subjects that drank water from contaminated source is contained in Table 2 . The subjects consisted of 7 residents of peri-urban area who had used the same water from busted/perforated pipes for over a period of one year. Subjects' age ranged from 2 to $>60$ years. All subjects, except the $>60$ years age woman who had recently visited and spent only 3 weeks then, were positive with high titre (>1/160) and blood isolates of Salmonella enterica enterica typhi. The rate of subjects infected by age range was as follows: 0 - 10 years (50.0\%), 11 - 20 years (33.3\%) and 41 - 50 years (16.7\%). There was no subject age range of 21 to 40 years within the household then. Table 3 shows the rate of Salmonella isolates from 1000 water samples analysed, consisting of 200 each of 5 different water sources. Salmonella species were mostly prevalent in well water (30.0\%). The rate of isolation of Salmonella enterica from water of other sources was as follows: bottled water (3.5\%), sachet water (6.0\%), pipe-borne water (8.5\%), and tank water (15.0\%). Table 4 shows the relative risk and the attack rate resulting from often drinking water from a particular source. Consumption of well water often, gave rise to highest attack rate (60.0\%) of typhoid fever infection. The relative risk (RR) was 2.7. There was no risk of infection presented in consumption of only boiled water. The attack (incidence) rate of often consuming water from other sources was as follows: filtered (18.8\%), stream (22.2\%), tank (26.6\%), pipe-borne (37.1\%), sachet (38.7\%).

\section{Discussion}

Some cases of typhoid infection were obviously transmitted through carrier contact as recorded in this study. Most of these subjects may have been individuals that carried out the domestic duties such as cooking and did not apply the required hygienic measures they most likely transmitted the bacilli to other members of the family. 
Table 1. Carrier contact case rate of subjects.

\begin{tabular}{cccccc}
\hline $\begin{array}{c}\text { Household } \\
\text { Infected }\end{array}$ & $\begin{array}{c}\text { Subjects within } \\
\text { Households }\end{array}$ & $\begin{array}{c}\text { Infected } \\
\text { Subjects (\%) }\end{array}$ & Carriers (\%) & $\begin{array}{c}\text { Exposed } \\
\text { Subjects (\%) }\end{array}$ & $\begin{array}{c}\text { Subjects Infected } \\
\text { by Contacts (\%) }\end{array}$ \\
\hline 1 & 5 & $1(20.0)$ & $1(20.0)$ & $4(80.0)$ & $1(25.0)$ \\
2 & 5 & $0(0.0)$ & $1(20.0)$ & $4(80.0)$ & $0(0.0)$ \\
3 & 4 & $1(25.0)$ & $0(0.0)$ & $0(0.0)$ & $0(0.0)$ \\
4 & 4 & $1(25.0)$ & $0(0.0)$ & $0(0.0)$ & $0(0.0)$ \\
5 & 4 & $1(25.0)$ & $0(0.0)$ & $0(0.0)$ & $0(0.0)$ \\
6 & 6 & $0(0.0)$ & $3(50.0)$ & $3(50.0)$ & $0(0.0)$ \\
7 & 4 & $1(25.0)$ & $2(50.0)$ & $2(50.0)$ & $1(50.0)$ \\
8 & 5 & $3(60.0)$ & $1(20.0)$ & $4(80.0)$ & $3(75.0)$ \\
9 & 4 & $3(75.0)$ & $1(25.0)$ & $3(75.0)$ & $3(100.0)$ \\
10 & 4 & $2(50.0)$ & $0(0.0)$ & $0(0.0)$ & $0(0.0)$ \\
11 & 2 & $2(100.0)$ & $0(0.0)$ & $0(0.0)$ & $0(0.0)$ \\
12 & 3 & $2(66.7)$ & $0(0.0)$ & $0(0.0)$ & $0(0.0)$ \\
13 & 4 & $1(25.0)$ & $1(25.0)$ & $3(0.0)$ & $1(33.3)$ \\
14 & 3 & $2(66.7)$ & $0(0.0)$ & $0(0.0)$ & $0(0.0)$ \\
15 & 3 & $2(66.7)$ & $0(0.0)$ & $0(0.0)$ & $0(0.0)$ \\
Total & $\mathbf{6 0}$ & $\mathbf{2 2 ( 3 6 . 7 )}$ & $\mathbf{1 0})$ & $\mathbf{2 3}(\mathbf{3 8 . 0})$ & $\mathbf{9 ( 3 9 . 1 )}$ \\
\hline
\end{tabular}

No. of exposed subjects $=$ No. of infected subtracted from number living within the household. No. infected by contact $=$ No. infected who have been in contact with (exposed to) carriers. Rate (\%) infected by contact is calculated per number of exposed. Rate of infected, carriers and exposed are each calculated per number living within household.

Table 2. Cohort/surveillance study of subjects drinking from contaminated pipe-borne water source.

\begin{tabular}{cccc}
\hline Age Range of Subjects (Years) & Subjects Tested & Positives (\%) & Negatives (\%) \\
\hline $0-10$ & 3 & $3(50.0)$ & $0(0.0)$ \\
$11-20$ & 2 & $2(33.3)$ & $0(0.0)$ \\
$21-30$ & 0 & $0(0.0)$ & $0(0.0)$ \\
$31-40$ & 0 & $0(0.0)$ & $0(0.0)$ \\
$41-50$ & 1 & $1(16.7)$ & $0(0.0)$ \\
$51-60$ & 0 & $0(0.0)$ & $0(0.0)$ \\
$61-70$ & 1 & $0(0.0)$ & $1(100.0)$ \\
Total & 7 & $\mathbf{6 ( 8 5 . 7 )}$ & $\mathbf{1 ( 1 4 . 3 )}$ \\
\hline
\end{tabular}

Table 3. Distribution of Salmonella enterica in water samples from various sources.

\begin{tabular}{ccc}
\hline Water Sources & Total Sample Analysed & Salmonella enterica (\%) \\
\hline Bottled Water & 200 & $7(3.5)$ \\
Sachet Water & 200 & $12(6.0)$ \\
Pipe-Borne Water & 200 & $17(8.5)$ \\
Surface Tank Water & 200 & $30(15.0)$ \\
Well Water & 200 & $60(30.0)$ \\
Total & 1000 & $126(12.6)$ \\
\hline
\end{tabular}


Table 4. Relative risks and infection rates for domestic water consumption.

\begin{tabular}{ccc}
\hline Source of Water & Relative Risks & Attack Rates (\%) \\
Boiled & 0 & 0.0 \\
Filtered & 0.4 & 18.8 \\
Stream & 0.5 & 22.2 \\
Tank & 0.5 & 26.6 \\
Pipe-Borne & 1 & 37.1 \\
Sachet & 1.2 & 38.7 \\
Well & 2.7 & 60 \\
\hline
\end{tabular}

Most of these subjects easily transmitted the disease because they were obviously chronic carriers; hence they confessed not having any symptoms over the years. This goes to confirm the report by Xavier [16] that though infected persons shed S. typhi in their faeces from the first week of illness through convalescence and transient carriers excrete S. typhi in their faeces or urine for only weeks or months; chronic carriers shed from $10^{6}$ to $10^{11}$ microorganisms per gram of feces over many years. Studies in Lagos, Nigeria by Smith et al. [17], showed that $5.7 \%$ food handlers had S. typhi in contrast to the $16.7 \%$ carriers in this study who were directly exposed by contact.

Drinking of infected water was mostly found to be a risk factor in acquisition of Salmonella infection in this study. At Sokoto State in Northern part of Nigeria, Ameh and Okpara [18] also discovered that drinking water was the most likely source of typhoid irrespective of the source (stream, pipe-borne, well and commercial water). Salmonella enterica was isolated at high rate from the well water, tank and pipe-borne water. The well water may have been contaminated because of high bacterial load that may have ensued from some septic tanks sipping into the source. This discovery was also made by Bhutta [19] occasionally waste and heaps of refuse or sewage drain into broken water pipes or surface water system that supply the public. The high rate of isolation from tank water shows that such tank water may have been collected from surface water, streams or even from untreated bore-hole water sources. Pipe-borne water was easily infected too. The water pipes serving as common domestic water source was found to be contaminated as a result of negative pressure inside the pipes created by intermittent water supply. Most of these pipes were laid about seven decades ago and have been perforated or damaged. Again most pipes are laid within the water drainage (gutter) paths. In this study the relative risk of consumption of well water (60\%), sachet water (38.7\%) and pipe-borne water (37.1\%) was also found to be high giving rise to high rate of attack of typhoid fever. At Ilorin, North West Nigeria, a study revealed significant titre of antibodies to Salmonella in subjects whose source of drinking water were sachet water (39.6\%), bore hole (37.5\%) and tap water (37.0\%) but lower antibody titre (26.6\%) was observed in those drinking treated water [20]. The attack rate obtained in this study at Enugu was similar to the incidences in the findings at Ilorin. Attack rate of well was higher than bore hole being that shallow wells were easily contaminated by soil matters and feaces, probably, from septic tanks. The infection rate obtained here was directionally proportional to the risk of consumption. The result of the cohort/survilliance study of subjects fed from contaminated water source over a period of time gave a significantly high rate $(p<0.05)$ of typhoid fever disease among the consumers.

Typhoid and paratyphoid fevers are common in underdeveloped and developing regions, principally owing to the problem of unsafe drinking-water, inadequate sewage disposal and flooding. Public health interventions to prevent typhoid and paratyphoid include: health education about personal hygiene, especially regarding handwashing after toilet use and before food preparation; provision of a safe water supply; proper sanitation systems and excluding disease carriers from food handling.

\section{Conclusion}

The continuance exposure to contaminated water source may be consistent to incessant and relapsing typhoid fever attacks in exposed individuals. Where these hygienic conditions are lacking, the probability of fecal contamination of water and food remains high and so is the incidence of typhoid. 


\section{References}

[1] Kariuki, S., Revathi, G., Muyodi, J., Mwituria, J., Munyalo, A. and Mirza, S. (2004) Characterization of MultidrugResistant Typhoid Outbreaks in Kenya. Journal of Clinical Microbiology, 42, 1477-1482. http://dx.doi.org/10.1128/JCM.42.4.1477-1482.2004

[2] Issack, M.I. (2005) Epidemiology of Typhoid Fever in Mauritius. Journal of Travel Medicine, 1295, 270-276. http://dx.doi.org/10.2310/7060.2005.12506

[3] Wasfy, M.O., Frenck, R., Ismail, T.F., Mansour, H., Malone, J.L. and Mahoney, M. (2002) Trends of Multiple-Drug Resistance among Salmonella Serotype Typhi Isolates during a 14-Year Period in Egypt. Clinical Infectious Diseases, 35, 1265-1268. http://dx.doi.org/10.1086/343052

[4] Akinyemi, K.O., Bamiro, B.S. and Coker, A.O. (2007) Salmonellosis in Lagos, Nigeria: Incidence of Plasmodium Falciparum-Associated Co-Infection, Patterns of Antimicrobial Resistance, and Emergence of Reduced Susceptibility to Fluoroquinolones. Journal of Health Population and Nutrition, 25, 351-358.

[5] Nkemngu, N.J., Asonganyi, E.D. and Njude, A.L. (2005) Treatment Failure in a Typhoid Patient Infected Nalidixic Acid Resistant S. enterica Serovar Typhi with Reduced Susceptibility to Ciprofloxacin: A Case Report from Cameroon. British Medicals and infectious Disease, 5, 49.

[6] Bhan, M.K., Bahl, R. and Bhatnagar, S. (2005) Typhoid and Paratyphoid Fever Lancet, 366, 749-762. http://dx.doi.org/10.1016/S0140-6736(05)67181-4

[7] Huckstep, R.L. and Wright, F.J. (2002) The Salmonellae. S. Livingston Ltd., Edinburgh and London, 25-34.

[8] Reller, M.E., Olsen, S.J., Kressel, A.B., Moon, T.D., Kubota, K.A., Adcock, M.P., et al. (2003) Sexual Transmission of Typhoid Fever: A Multistate Outbreak among Men Who Have Sex with Men. Clinical Infectious Disease, 37, 141144. http://dx.doi.org/10.1086/375590

[9] Brooks, G.F., Butel, J.S. and Morse, S.A. (2004) The Salmonella-Arizona Group. Medical Micrbiology. 23rd Edition, McGraw Hill, New York, 256-260.

[10] Ismail, T.F. (2006) Rapid Diagnosis of Typhoid Fever. Indian Journal of Medical Research, 123, 489-492.

[11] World Health Organization (2003) Typhoid Vaccine, Immunization, Vaccines and Biological. Geneva. http://ww.who.int/vaccines/en/typhoidShtml\#impact

[12] Luxemburger, C., Chau, M.C., Mai, N.L., Wain, J., Tran, T.H. and Simpson, J.A. (2001) Risk Factors for Typhoid Fever in the Mekong Delta, Southern Viet Nam: A Case-Control Study. Transactions of the Royal Society of Tropical Medicine and Hygiene, 95, 19-23. http://dx.doi.org/10.1016/S0035-9203(01)90318-9

[13] Kumar, K.S., Harada, H. and Karn, S. (2002) Field Survey on Water Supply, Sanitation and Associated Health Impacts in Urban Poor Communities-A Case from Mumbai City, India. Water Science and Technology, 46, 269-275.

[14] Tran, H.H., Bjune, G., Nguyen, B.M., Rottingen, J.A., Grais, R.F. and Guerin, P.J. (2005) Risk Factors Associated with Typhoid Fever in Son La Province, Northern Vietnam. Transactions of the Royal Society of Tropical Medicine and Hygiene, 99, 819-826. http://dx.doi.org/10.1016/j.trstmh.2005.05.007

[15] Adeleke, O.E., Adepoju, T.J. and Ojo, D.A. (2006) Prevalence of Typhoid Fever and Antibiotic Susceptibility Pattern of Its Causative Agent Salmonella typhi. Nigerian J. Microbiol., 20, 1191-1197.

[16] Xavier, G. (2006) Management of Typhoid and Paratyphoid Fevers. Nursing Times, 102, 49-51.

[17] Smith, S.I., Goodluck, H.T., Fowora, B.M. and Omonigbehin, E. (2008) Prevalence of Salmonella typhi among Food Handlers from Bukkas in Nigeria. Moleculer Biology and Biotechnology Division, Nigerian Institute of Medical Research. British Journal of Biomedical Science, 65, 158-160.

[18] Ameh, I.G. and Opara, W.E.K. (2004) Typhoid: A Record of Cases in Sokoto, Nigeria. Pakistan Journal of Biological Sciences, 7, 1177-1180. http://dx.doi.org/10.3923/pjbs.2004.1177.1180

[19] Bhutta, Z.A. (2006) Current Concepts in the Diagnosis and Treatment of Typhoid Fever. British Medical Journal, 333, 78-82. http://dx.doi.org/10.1136/bmj.333.7558.78

[20] Okonko, I.O., Soleye, F.A., Eyarefe, O.D., Amusan, T.A., Abubakar, M.J., Adeyi, A.O., et al. (2010) Prevalence of Salmonella typhi among Patients in Abeokuta, South-Western Nigeria. British Journal of Pharmacology and Toxicology, 1, 6-14. 